\title{
Editorial
}

Welcome to another issue of Library and Information Research, which begins with two examples of how CILIP's Library and Information Research Group (LIRG) aims to support its members and to support research in the field.

Our first article is by Julie Doran, the successful candidate for this year's LIRG bursary to attend the CILIP conference in Liverpool. Her report describes her conference experiences, offering an insight into the keynote presentations and an overview the main themes, as well as sharing her thoughts about the venues, the city and the conference social events.

Jessica Elmore was the winner of the 2014 LIRG student prize, awarded for her Master's dissertation about information literacy within home educating families. In an Invited Contribution, and writing with Peter Stordy, she reports on her dissertation findings, suggesting that families can be seen as communities of practice; showing the importance of reflection in information literacy and suggesting ways in which the experiences of home educating families may challenge orthodox educational models of information literacy.

The two refereed articles featured in this issue demonstrate the international reach of Library and Information Research. The first of these articles describes an ejournals availability study at the University of Zimbabwe, written by Thembani Malapela and Karin de Jager. This study emphasises the significance of donor programmes, consortial arrangements and publisher-led subsidised access schemes for the availability of e-journals in universities in Africa. Zhixian Yi's article examines approaches to change management amongst library managers, and offers some insights into the preferred strategies of academic library directors in the USA.

Three book reviews cover a wide range of current topics, from Joanna Baines' review of Sidney Berger on Rare Books and Special Collections, to Louise EllisBarrett on Kenneth Varnum's guide to The Top Ten Technologies Every Librarian Needs to Know and Anne Shelley's evaluation of Dee Ann Allison on The Patron Driven Library.

If you are inspired by articles in this issue and have research findings of your own which you would like to share, please do consider writing for Library and Information Research.

\section{Angharad Roberts}




\section{Open access and copyright}

Library and Information Research is an open access journal. A freely available copy of this paper may be downloaded from the journal's website: http://www.lirgjournal.org.uk.

Copyright and associated moral rights in works published in Library and Information Research are retained by the author(s) but this paper may be used freely, with proper attribution, in educational and other non-commercial settings. 